\title{
NSW Annual Immunisation Coverage Report, 2010
}

\author{
Brynley Hull ${ }^{\mathrm{A}, \mathrm{D}}$, Aditi Dey ${ }^{\mathrm{A}}$, \\ Sue Campbell-Lloyd ${ }^{\mathrm{B}}$, Robert I. Menzies ${ }^{\mathrm{A}, \mathrm{C}}$ \\ and Peter B. McIntyre ${ }^{\mathrm{A}, \mathrm{C}}$ \\ ${ }^{\mathrm{A}}$ National Centre for Immunisation Research and Surveillance, \\ The Children's Hospital at Westmead \\ ${ }^{\mathrm{B}}$ AIDS and Infectious Diseases Branch, NSW Department \\ of Health \\ ${ }^{\mathrm{C}}$ Sydney Medical School, The University of Sydney \\ ${ }^{\mathrm{D} C o r r e s p o n d i n g ~ a u t h o r . E m a i l: ~ b r y n l e y h @ c h w . e d u . a u ~}$
}

This is the second New South Wales (NSW) Annual Immunisation Coverage Report. This series of annual reports provides information on trends and issues in immunisation coverage in NSW to facilitate the monitoring of NSW immunisation programs. This report uses the longstanding international practice of reporting coverage at key milestone ages to measure coverage against national benchmarks and to track trends over time. It is adapted from annual national immunisation reports published since 2009. ${ }^{1}$

High levels of reporting to the Australian Childhood Immunisation Register are maintained by a system of incentive payments for immunisation providers and carers. These have been discussed in detail elsewhere. ${ }^{2}$ However, changes to immunisation policy, the incentive payment system and changes to the 'fully immunised' coverage algorithms may have an impact on reported vaccination coverage; some recent changes are highlighted in Box 1 and also referred to in this report.

The Australian Childhood Immunisation Register was established on 1 January 1996 by incorporating demographic data from Medicare on all enrolled children aged less than 7 years. ${ }^{3}$ The operations of the Australian Childhood Immunisation Register have been discussed in detail elsewhere. $^{2}$

Table 1 presents the vaccines delivered through the NSW Immunisation Program for children in 2010. No new vaccines were introduced into the NSW Immunisation Program during 2010.

\section{Methods \\ Measuring immunisation coverage using the Australian Childhood Immunisation Register}

The cohort method has been used for calculating coverage at the population level (national and state/territory) ${ }^{4}$ since the inception of the Australian Childhood Immunisation Register. Cohort immunisation status is assessed at 12 months of age (for vaccines due at 6 months), 24 months of age (for vaccines due at 12 months), and 5 years of age (for vaccines due at 4 years). A 3 -month lag period is allowed for the late notification of immunisations to the Australian Childhood Immunisation Register. ${ }^{4}$ If a child's records indicate receipt of the last dose of a vaccine that requires more than one dose to complete the series, it is 
Box 1. Recent significant changes in immunisation policy, immunisation incentives and coverage calculation algorithms

December 2009 - Changes in the coverage calculation algorithms that tightened the rules regarding receipt of Haemophilus influenzae type $b$ and hepatitis B vaccines for children aged 12 and 24 months to lead to more accurate measures of Haemophilus influenzae type $b$ and hepatitis $B$ vaccine coverage in Australia.

October 2009 - The recommendation by the Australian Technical Advisory Group on Immunisation that the fourth dose of diphtheria, tetanus and acellular pertussis (DTPa)-containing vaccine can be given from $3 \frac{1}{2}$ years of age instead of the previously recommended 4 years of age.

March 2009 - The recommendation by NSW Health and the Australian Technical Advisory Group on Immunisation to parents and immunisation providers to consider bringing the first dose of DTPa forward to 6 weeks of age to provide earlier protection.

January 2009 - Changes to the overdue rules so that children were classified as overdue for pre-school boosters at 4 years and 1 month instead of the previous 5 years of age. This applied to parental and provider incentive payments.

The Maternity Immunisation Allowance changed from a full payment at 18-24 months of age to being paid in two instalments: the first when the child is fully immunised and aged between 18 and 24 months; and the second when the child is fully immunised and aged between 4 and 5 years. This payment applied only to children who had not yet already received the full payment at 2 years of age.

October 2008 - The General Practice Immunisation Incentive Service Incentive Payment ( $\$ 18.50$ for completing a schedule point) ceased. Information payments of $\$ 6$ were retained.

December 2007 - Coverage algorithm for immunisations due at 4 years of age changed to assess children at 5 years, not 6 years.

Table 1. Schedule of vaccines delivered through the NSW Immunisation Program, to children, adolescents and adults in 2010

\begin{tabular}{|c|c|c|c|c|c|c|c|c|c|c|}
\hline Age & \multicolumn{10}{|c|}{ Vaccine } \\
\hline \multicolumn{11}{|c|}{ Childhood vaccines } \\
\hline Birth & Нер B & & & & & & & & & \\
\hline 2 months & Hep B & DTPa & $\mathrm{Hib}$ & Polio & & & $7 \mathrm{vPCV}$ & & Rotavirus & \\
\hline 4 months & Hep B & DTPa & $\mathrm{Hib}$ & Polio & & & $7 v P C V$ & & Rotavirus & \\
\hline 6 months & Hep B & DTPa & $\mathrm{Hib}$ & Polio & & & $7 v P C V$ & & & \\
\hline 12 months & & & $\mathrm{Hib}$ & & MMR & & & Men C & & \\
\hline 18 months & & & & & & VZV & & & & \\
\hline 4 years & & DTPa & & Polio & MMR & & & & & \\
\hline \multicolumn{11}{|c|}{ Adolescent vaccines } \\
\hline 12 years & Hep B & dTpa & & & & VZV & HPV & & & \\
\hline 15 years & & dTpa & & & & & & & $\mathrm{Flu}^{\mathrm{a}, \mathrm{c}}$ & $23 v P P V^{b}$ \\
\hline \multicolumn{11}{|c|}{ Adult vaccines } \\
\hline$\geq 50$ years & & & & & & & & & $\mathrm{Flu}^{\mathrm{a}, \mathrm{c}}$ & $23 v P P V^{a}$ \\
\hline 65 years & & & & & & & & & $\mathrm{Flu}^{\mathrm{c}}$ & 23vPPV \\
\hline \multicolumn{11}{|c|}{$\begin{array}{l}\text { Hep B: hepatitis B vaccine; DTPa: diphtheria, tetanus and acellular pertussis-containing vaccine; } d T p a: \text { adolescent and adult formul } \\
\text { Hib: Haemophilus influenzae type b vaccine; MMR: measles-mumps-rubella vaccine; VZV: varicella zoster virus vaccine; } 7 \mathrm{vPCV} \text { : 7-val } \\
\text { pneumococcal conjugate vaccine; Men C: meningococcal C vaccine; HPV: human papilloma virus vaccine (females only); Flu: influe } \\
\text { 23vPPV: } 23 \text {-valent pneumococcal polysaccharide vaccine } \\
\text { aAll Aboriginal adults only } \\
{ }^{b} \text { Aboriginal adults with medical risk factors } \\
\text { cAnnual vaccination, all aged } \geq 6 \text { months with medical risk factors, Aboriginal adults } \geq 15 \text { years, non-Aboriginal adults } \geq 65 \text { years } \\
\text { Source: National Immunisation Program Schedule. }\end{array}$} \\
\hline
\end{tabular}




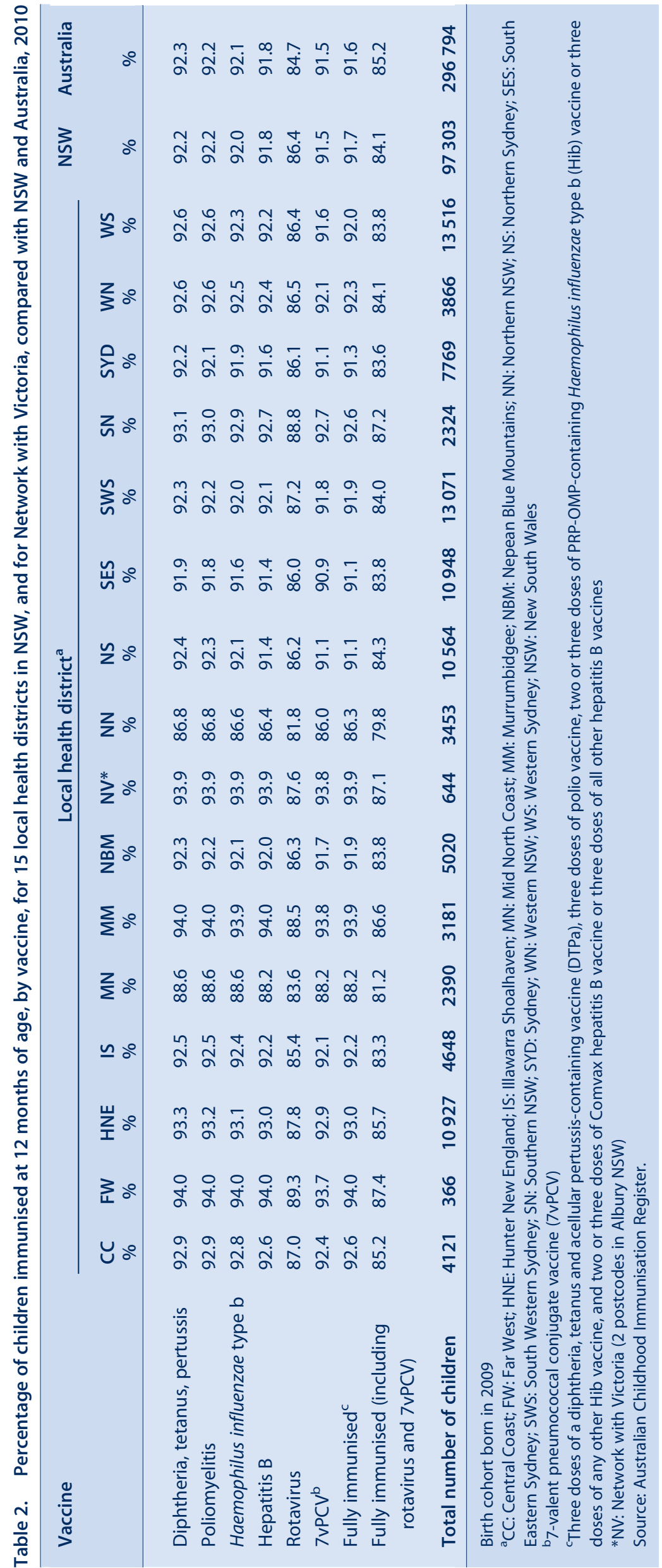




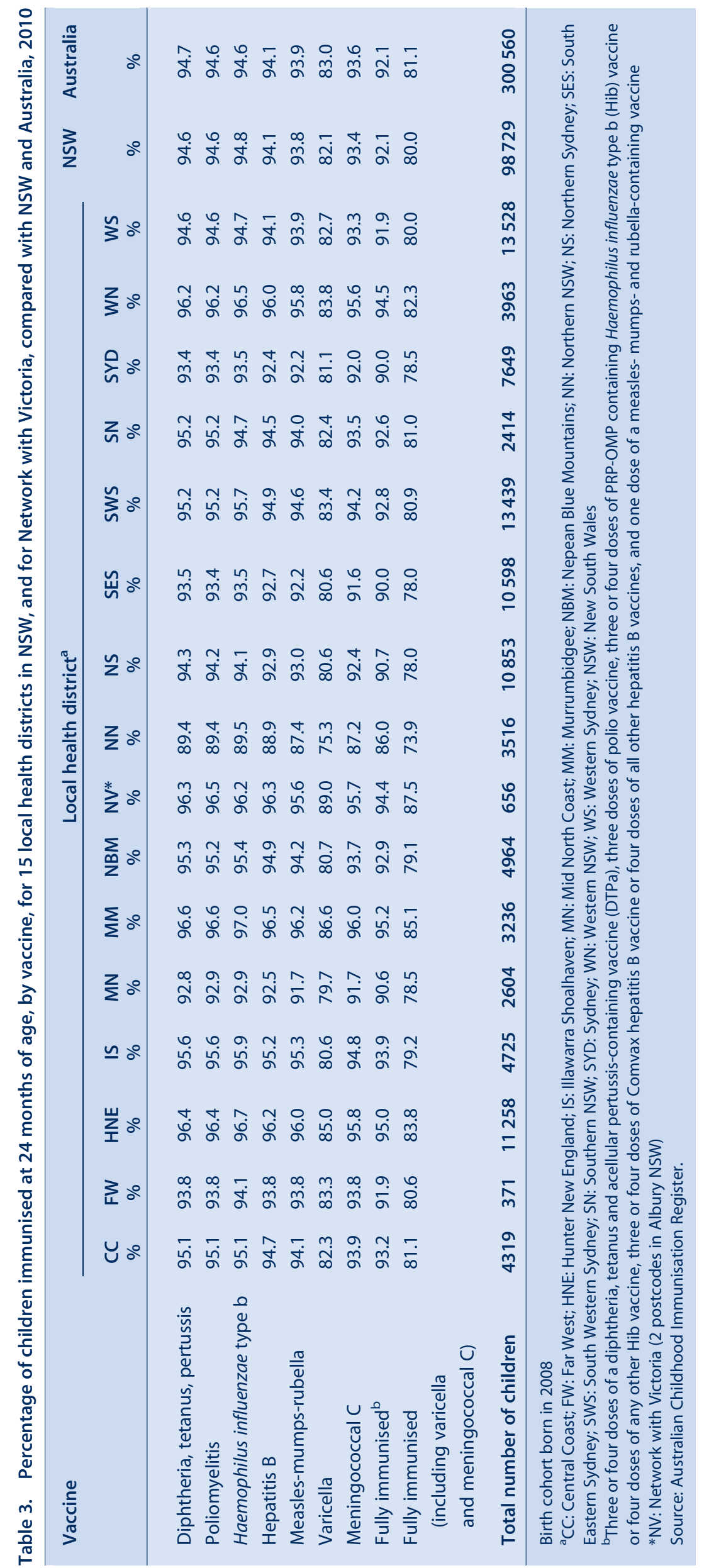




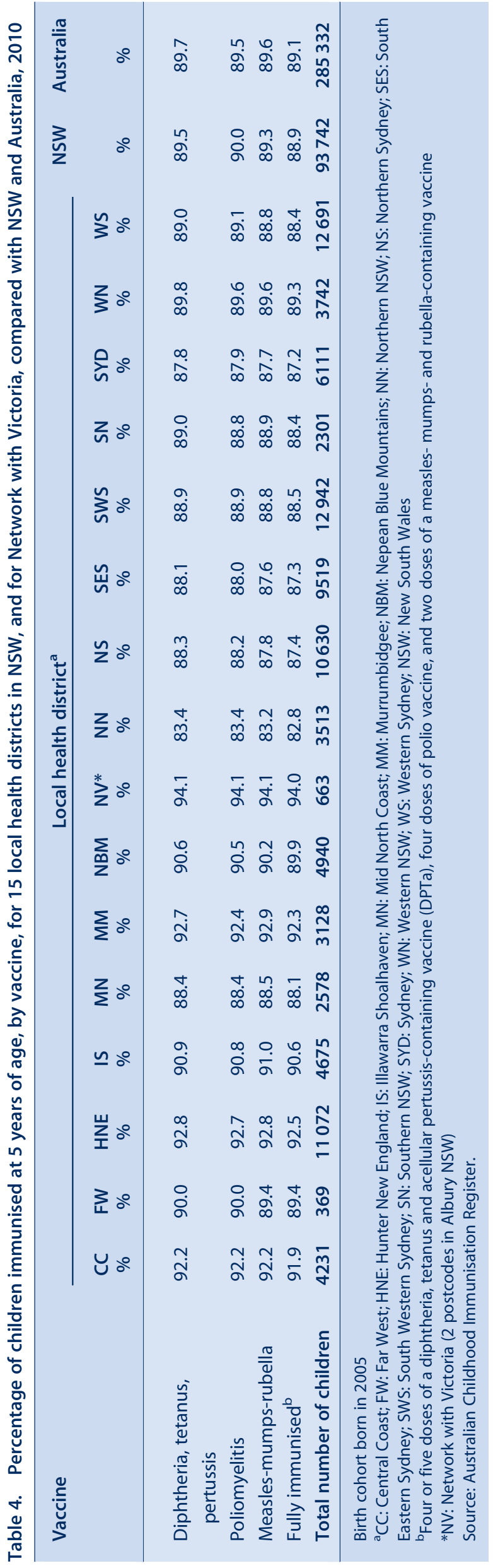

assumed that earlier vaccinations in the sequence have been given. This assumption has been shown to be valid. ${ }^{5,6}$

The proportion of children designated as 'fully immunised' was calculated using the number of Medicare-registered children who were completely immunised with the vaccines of interest by the designated age as the numerator and the total number of Medicare-registered children in the age cohort as the denominator. 'Fully immunised' at 12 months of age was defined as a child having a record on the Australian Childhood Immunisation Register of three doses of a diphtheria, tetanus and pertussis (DTP)containing vaccine, three doses of polio vaccine, three doses of Haemophilus influenzae type b (Hib) vaccine and three doses of hepatitis B vaccine. 'Fully immunised' at 24 months of age was defined as three or four doses of a DTP-containing vaccine, three doses of polio vaccine, four doses of Hib vaccine, three doses of hepatitis B vaccine, and one dose of a measles- mumps- rubellacontaining (MMR) vaccine. 'Fully immunised' at 5 years of age was defined as four or five doses of a DTPcontaining vaccine, four doses of polio vaccine and two doses of an MMR-containing vaccine.

Immunisation coverage estimates were also calculated for individual National Immunisation Program vaccines, including those not included in calculations for incentive payments and 'fully immunised' status. They were: the third dose of 7-valent pneumococcal conjugate vaccine $(7 \mathrm{vPCV})$ and the second dose of rotavirus vaccine by 12 months of age; and one dose each of varicella and meningococcal $\mathrm{C}$ vaccines by 24 months of age.

\section{Timeliness}

Age-appropriate immunisation was defined as receipt of a scheduled vaccine dose within 30 days of the recommended age. We categorised vaccination at 1-6 months or more than 6 months after the recommended age as delayed. All children included in the analysis were old enough to potentially experience delays in immunisation greater than 6 months for immunisation due by 24 months of age or earlier. Timeliness of different vaccines and doses was also compared by plotting the cumulative percentage receiving each vaccine dose by age, with the proportion ever immunised set as $100 \%$.

\section{Local health districts}

Immunisation coverage estimates and vaccination delay estimates are presented in this report by NSW local health district (LHD). LHDs were introduced in January 2011, replacing area health services. There are 18 LHDs in NSW, eight in metropolitan NSW, seven in rural and regional NSW, two specialist networks focusing on Children's and Paediatric Services, and one specialist network focusing on Forensic Mental Health. Another geographical area, 


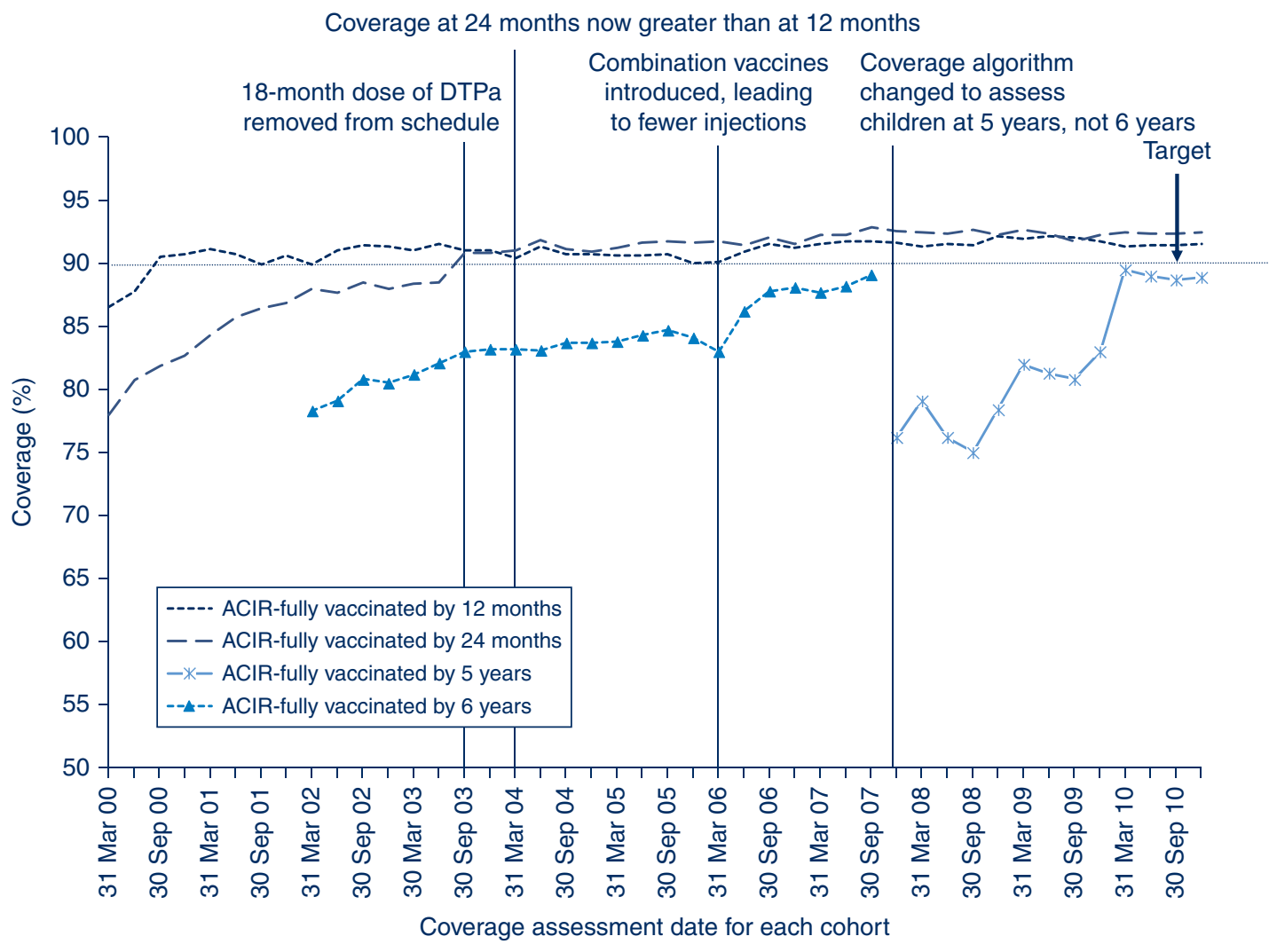

Figure 1. Trends in 'fully immunised'a,b,c vaccination coverage, NSW, 2000-2010, for four age cohorts

${ }^{a}$ Three doses of a diphtheria, tetanus and acellular pertussis-containing (DTPa) vaccine, three doses of polio vaccine, two or three doses of PRP-OMP-containing Haemophilus influenzae type $b$ (Hib) vaccine or three doses of any other Hib vaccine, and two or three doses of Comvax hepatitis B vaccine or three doses of all other hepatitis B vaccines.

${ }^{\mathrm{b}}$ Three or four doses of a DTPa-containing vaccine, three doses of polio vaccine, three or four doses of PRP-OMP-containing Hib vaccine or four doses of any other Hib vaccine, three or four doses of Comvax hepatitis B vaccine or four doses of all other hepatitis B vaccines, and one dose of a measles, mumps and rubella (MMR)-containing vaccine.

${ }^{\mathrm{C}}$ Four or five doses of a DTPa-containing vaccine, four doses of polio vaccine, and two doses of an MMR-containing vaccine. ACIR: Australian Childhood Immunisation Register

Source: Australian Childhood Immunisation Register.

Network with Victoria, consists of two postcodes (2640 and 2641) both of which are in Albury NSW.

\section{Aboriginal status}

Indigenous status on the Australian Childhood Immunisation Register is recorded nationally as 'Indigenous', 'nonIndigenous' or 'unknown', as reported by the child's carer to Medicare, or by the immunisation provider to the Australian Childhood Immunisation Register. For this report we considered two categories of children: 'Aboriginal' (Indigenous) and 'non-Aboriginal' (nonIndigenous). Children with unknown Aboriginal status were presumed to be 'non-Aboriginal'. Coverage estimate time trends are presented from 2004 only, due to poor rates of reporting of Aboriginal status before that time. ${ }^{7}$

\section{Small area coverage}

Coverage was calculated for Australian Bureau of Statistics (ABS)-defined statistical subdivisions. ${ }^{8}$ We chose
ABS-defined statistical subdivisions as areas to be mapped because they provide more detail than LHDs but are not too small to render maps unreadable (child population sizes for statistical subdivisions in NSW range from 90 to 7000 children). Maps were created using MapInfo mapping software (version 10, MapInfo Corporation, New York, USA) and the ABS Census Boundary Information. As postcode is the only geographical indicator on the Australian Childhood Immunisation Register, the ABS Postal Area to Statistical Local Area Concordance 2006 was used to match Australian Childhood Immunisation Register residential postcodes of the children to statistical subdivisions. ${ }^{9}$

\section{Conscientious objection and no vaccine recorded}

A child must be registered with Medicare before his or her parent(s) can lodge a conscientious objection to immunisation with the Australian Childhood Immunisation Register. Conscientious objectors are eligible for immunisation incentive payments without the need for immunisation, 


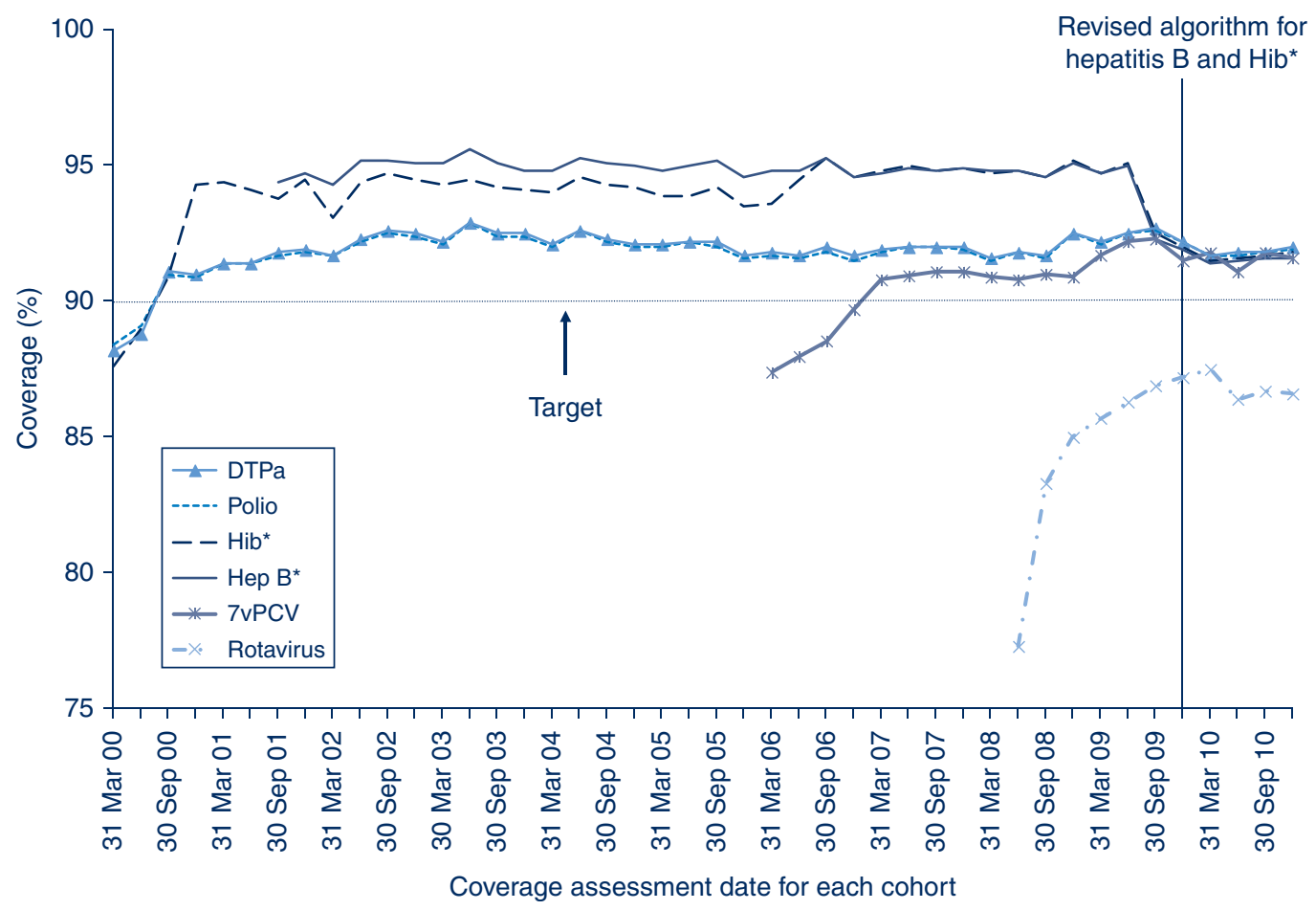

Figure 2. Trends in vaccination coverage estimates for individual vaccines at 12 months of age (third dose of DTPa, polio, hepatitis B, Hib, rotavirus and 7vPCV), NSW, 2000-2010

By 3-month birth cohorts born between 1 January 1999 and 31 December 2009. Coverage assessment date was 12 months after the last birth date of each cohort.

*Prior to September 2009, the algorithm stated that receipt of two or three doses of Haemophilus influenzae type b (Hib) and hepatitis B vaccines rendered a child 'fully immunised' for these vaccines. After September 2009, changes to the algorithm were made to tighten the rules regarding 'fully immunised' for Hib and hepatitis B vaccines.

7vPCV: 7-valent pneumococcal conjugate vaccine

DTPa: diphtheria, tetanus, pertussis (acellular) - paediatric formulation

Source: Australian Childhood Immunisation Register.

but parents may also object to immunisation but refuse to lodge any official objection. We used the percentage of children with no vaccines recorded on the Australian Childhood Immunisation Register as a proxy measure of the total number of children whose carers were opposed to immunisation, whether or not they are registered as such. Proportions of conscientious objectors and children with no vaccines recorded by LHD were calculated from the cohort of children registered with Medicare and born between 1 January 2004 and 31 December 2009; at the time of data extraction these children were aged between 12 and 72 months. We chose this cohort when calculating proportions so that children under the age of 12 months were not included, to allow sufficient time for registration of objection and to exclude infants late for vaccination.

\section{Coverage in the elderly and adolescents}

Influenza and pneumococcal vaccination coverage estimates in elderly people were obtained from the NSW Population Health Survey. This is a rolling random digit-dialled telephone survey, with vaccination status determined from patient recall at the time of the interview. Influenza and pneumococcal vaccination coverage estimates are based on 3568 and 3342 respondents in NSW, respectively. Methods and results are presented in more detail elsewhere. ${ }^{10}$ Coverage for vaccines given to adolescents was collected from the NSW School Immunisation Program. Vaccination status is recorded by school immunisation teams and counts collated by LHDs and NSW Health. The denominator is the school population, start of year enrolments. The coverage rates may underestimate the true vaccination coverage as they represent only those vaccinations received through the school program and do not include doses received from general practitioners or other immunisation providers. Methods are presented in more detail elsewhere. ${ }^{11}$

\section{Results}

\section{Overall coverage estimates}

In the majority of LHDs in NSW, coverage for all individual vaccines (except rotavirus) for the 12-month age group 


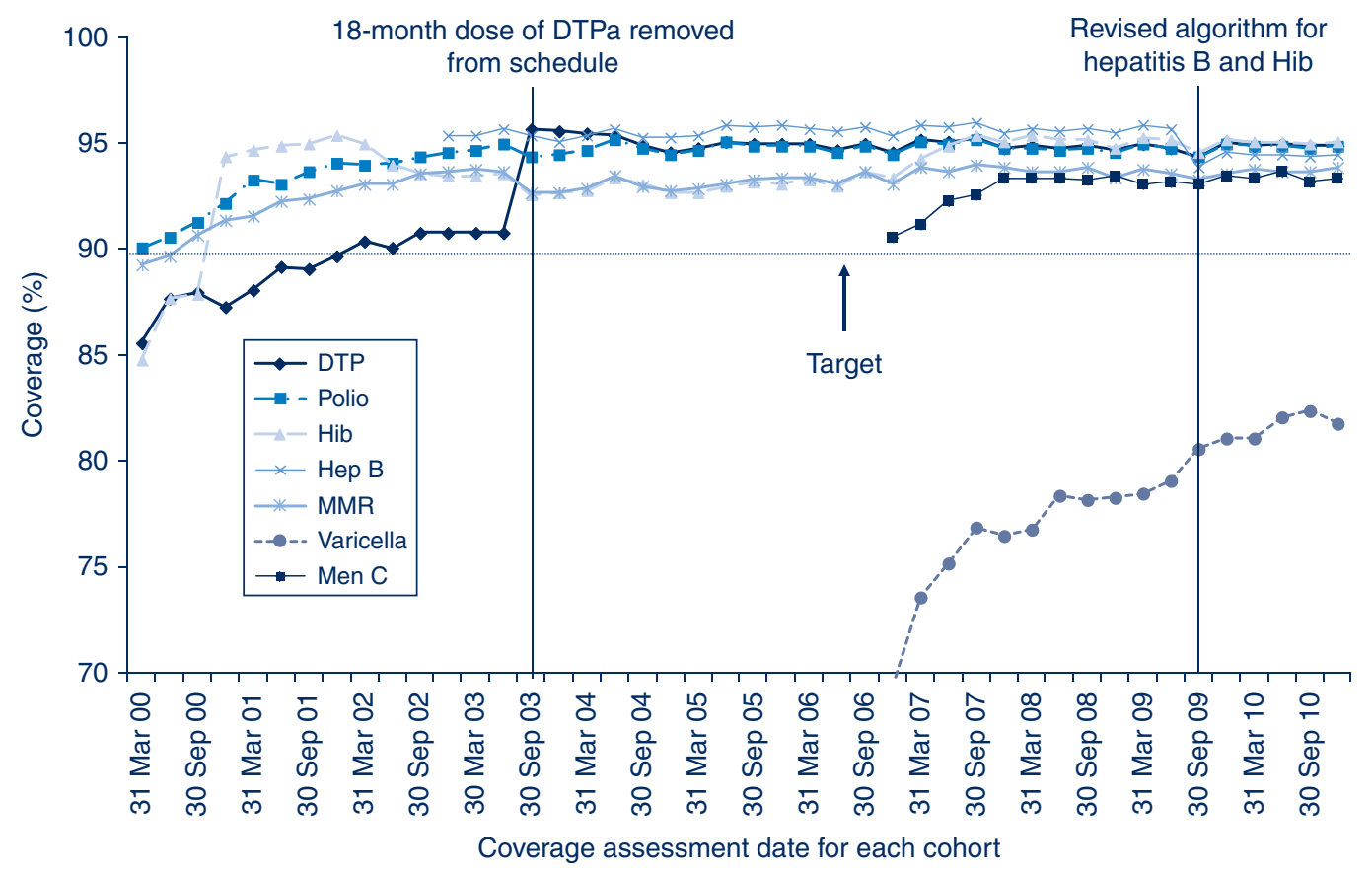

Figure 3. Trends in vaccination coverage estimates for individual vaccines at 24 months of age (DTPa, polio, hepatitis B, Hib, MMR, varicella, Men C), ${ }^{a}$ for NSW 3-month birth cohorts between 1999 and 2008

By 3-month birth cohorts born between 1 January 1999 and 31 December 2008. Coverage assessment date was 24 months after the last birth date of each cohort.

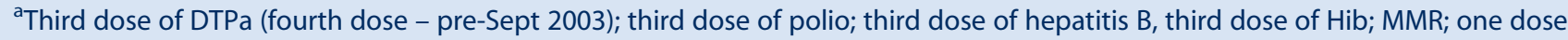
of varicella and one dose of Men C).

DTPa: diphtheria, tetanus, pertussis (acellular) - paediatric formulation

Hep B: hepatitis B

Hib: Haemophilus influenzae type b

Men C: meningococcal C

MMR: measles-mumps-rubella

Source: Australian Childhood Immunisation Register.

is greater than 90\%. Two LHDs (Mid North Coast and Northern NSW) had 12-month coverage estimates ranging from $81.8 \%$ to $88.6 \%$ for all individual vaccines for the 12-month age group (Table 2). Similarly, in all LHDs except Northern NSW, coverage for all individual vaccines (except varicella) for the 24-month age group is also higher than $90 \%$ (Table 3). Recorded coverage for the 5 -year age group is slightly below $90 \%$ for all vaccines (Table 4). Figure 1 shows time trends in 'fully immunised' childhood vaccination coverage at three milestone ages in NSW. The proportion 'fully immunised' at 1 and 2 years of age has been at high levels since 2003 whereas coverage at 5 years of age increased markedly in 2009 and 2010 .

\section{Coverage estimates for children aged less than 3 years}

In NSW before 2009, coverage for the 12-month and 24-month age groups for Hib and hepatitis B vaccines was greater than for DTPa and polio, due to a less stringent algorithm for calculating coverage. Since the change in algorithm in the latter half of 2009, coverage estimates for Hib and hepatitis B have lowered and become similar to those of DTPa and polio at just under 95\% (Figures 2 and 3). These newer estimates more accurately reflect the true proportion of children fully vaccinated for these vaccines.

Coverage for $7 \mathrm{vPCV}$ has remained at high levels, with an increase from $87.4 \%$ in March 2006 to $91.6 \%$ in the last cohort assessed in December 2010 (Figure 2). It was similar in all LHDs at greater than $90 \%$ except in the Mid North Coast and Northern NSW (Table 2).

Rotavirus vaccine was added to the National Immunisation Program in July 2007; coverage for two doses at 12 months of age was calculated only from the July 2008 quarter onwards. Coverage increased in NSW from $77.3 \%$ in July 2008 to $86.6 \%$ in December 2010 (Figure 2) and was lower and had greater variation between LHDs compared to other vaccines given at 2, 4 and 6 months of age (Table 2).

In 2010, coverage for the MMR and meningococcal C vaccines for the 24-month age group was around $94 \%$ and $93 \%$ respectively. Coverage for meningococcal $\mathrm{C}$ has remained at high levels since first calculated for NSW in 


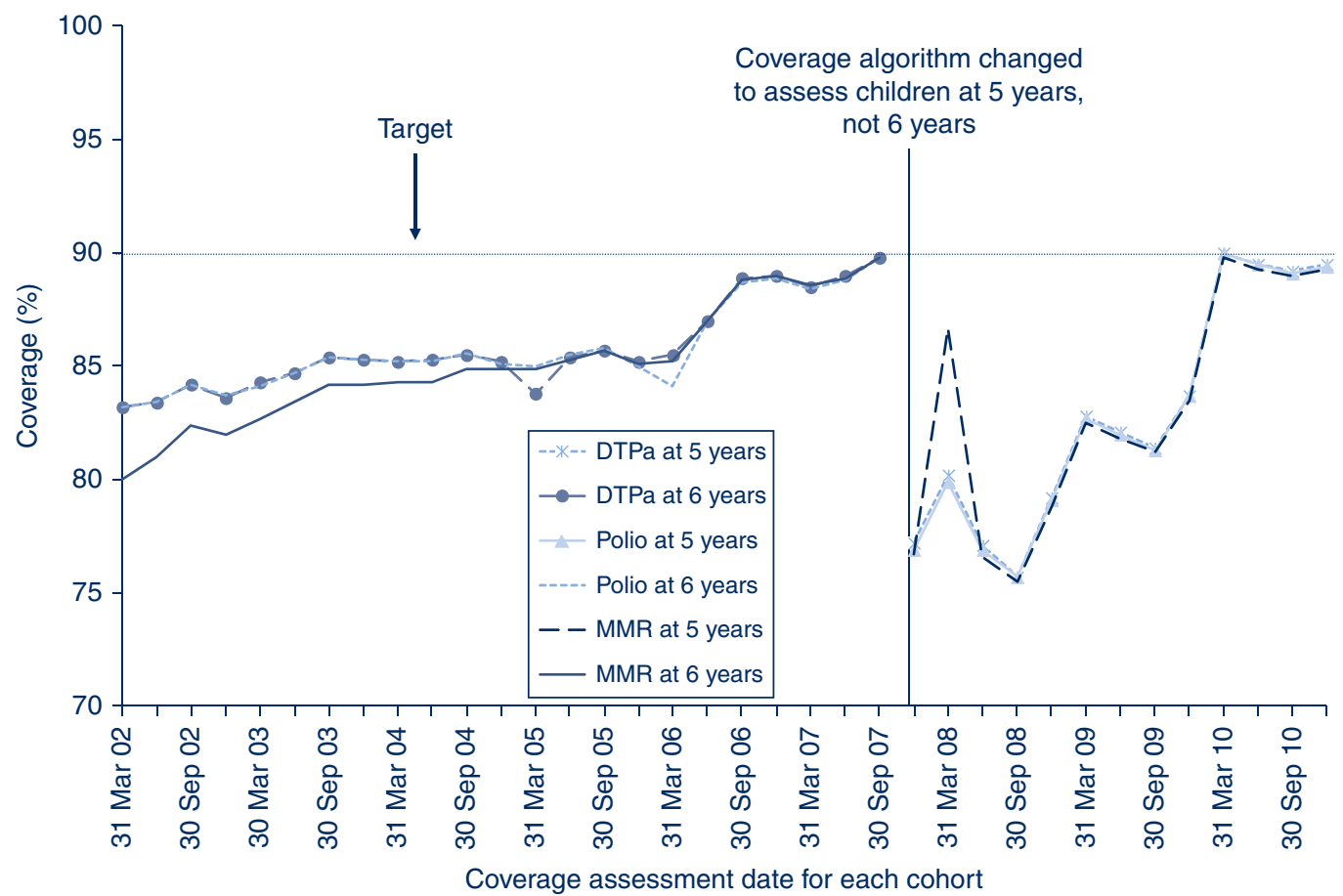

Figure 4. Trends in vaccination coverage estimates for individual vaccines (DTPa, polio and MMR) at 5 years of age (6 years up to December 2007)

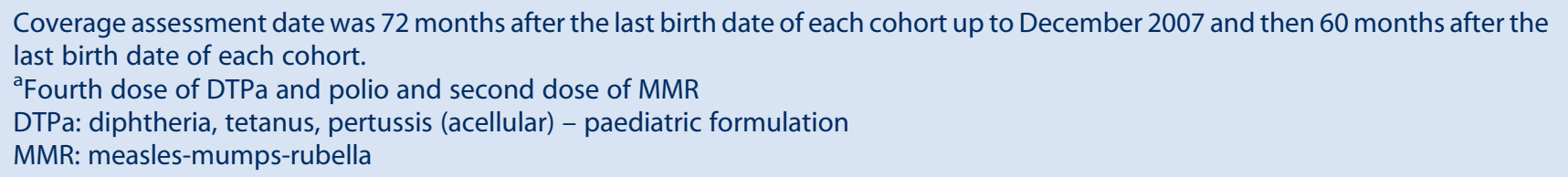

Source: Australian Childhood Immunisation Register.

early 2006 though it was added to the National Immunisation Program in January 2003. It was greater than $91 \%$ in all LHDs except Northern NSW (Table 3).

Varicella vaccine coverage for all LHDs was much lower than for meningococcal $\mathrm{C}$ (Table 3), ranging from $75.3 \%$ in Northern NSW to $89 \%$ in Albury (Network with Victoria).

\section{Coverage estimates for children aged 5-6 years}

The trends in childhood vaccination coverage in NSW for individual vaccines (DTPa, polio and MMR) at 6 years of age (5 years of age from December 2007) are shown in Figure 4. Coverage for all three vaccines was almost identical and remained steady across the whole period until mid-2006 when a sharp increase of almost 5\% was recorded, likely due to the introduction of combination vaccines. Coverage at 5 years of age was substantially lower than at 6 years of age due to the shorter time for the recording of delayed vaccinations. However, in 2010, the 5-year coverage for DTPa, polio and MMR increased markedly to be slightly above $89 \%$. The overall 'fully immunised' rate for 5-year coverage was approximately $89 \%$ in NSW, which was similar to the national
5 -year coverage rate of $89.1 \%$. All LHDs in NSW had more than $85 \%$ 5-year coverage rates for all vaccines, except Northern NSW which had approximately $83 \%$ (Table 4).

\section{Coverage estimates for Aboriginal children}

Vaccination coverage estimates for the three milestone ages for individual vaccines for Aboriginal status for 2010 are shown in Tables 5 and 6. These tables show that coverage is lower for Aboriginal children than nonAboriginal children at the 12-month and 5-year age milestones, but there was little difference at 24 months of age.

At 12 months of age, at the LHD level, coverage was lower among Aboriginal children in all LHDs except Northern Sydney (91.1\% non-Aboriginal; 100\% Aboriginal) and Central Coast (92.6\% non-Aboriginal; 93.0\% Aboriginal). The extent of the difference varied among LHDs, ranging from $0.1 \%$ to $12 \%$. However, by the age of 24 months, coverage disparities between Aboriginal and all other NSW children had almost disappeared in most LHDs, with the proportion 'fully immunised' at $91.5 \%$ for Aboriginal and $92.1 \%$ for all other NSW children (Tables 3 and 6). All LHDs in NSW had more than $90 \%$ coverage for Aboriginal 
Table 5. Vaccination coverage estimates for NSW children by age, disease and Aboriginal status, 2010

\begin{tabular}{|c|c|c|c|}
\hline Vaccine & Milestone age & Aboriginal & Non-Aboriginal \\
\hline \multirow[t]{3}{*}{ Diphtheria-tetanus-pertussis } & 12 months $^{\mathrm{a}}$ & 87.3 & 92.4 \\
\hline & 24 months $^{\mathrm{b}}$ & 94.3 & 94.7 \\
\hline & 5 years $^{c}$ & 84.8 & 89.6 \\
\hline \multirow[t]{3}{*}{ Poliomyelitis } & 12 months $^{a}$ & 87.2 & 92.4 \\
\hline & 24 months $^{\mathrm{b}}$ & 94.3 & 94.6 \\
\hline & 5 years $^{c}$ & 84.7 & 89.6 \\
\hline \multirow[t]{3}{*}{ Haemophilus influenza type b } & 12 months $^{\mathrm{a}}$ & 87.2 & 92.2 \\
\hline & 24 months $^{b}$ & 95.0 & 94.8 \\
\hline & 5 years $^{c}$ & $\mathrm{NI}$ & $\mathrm{NI}$ \\
\hline \multirow[t]{3}{*}{ Hepatitis B } & 12 months $^{\mathrm{a}}$ & 87.2 & 92.0 \\
\hline & 24 months $^{\mathrm{b}}$ & 94.3 & 94.1 \\
\hline & 5 years $^{c}$ & $\mathrm{NI}$ & $\mathrm{NI}$ \\
\hline \multirow[t]{3}{*}{ Measles-mumps-rubella } & 12 months $^{a}$ & $\mathrm{NI}$ & $\mathrm{NI}$ \\
\hline & 24 months $^{b}$ & 93.6 & 93.8 \\
\hline & 5 years $^{c}$ & 85.2 & 89.4 \\
\hline \multirow[t]{3}{*}{ Varicella } & 12 months $^{a}$ & $\mathrm{NI}$ & $\mathrm{NI}$ \\
\hline & 24 months $^{\mathrm{b}}$ & 81.0 & 82.1 \\
\hline & 5 years $^{c}$ & $\mathrm{NI}$ & $\mathrm{NI}$ \\
\hline \multirow[t]{3}{*}{ Meningococcal C } & 12 months $^{\mathrm{a}}$ & $\mathrm{NI}$ & $\mathrm{NI}$ \\
\hline & 24 months $^{\mathrm{b}}$ & 93.3 & 93.4 \\
\hline & 5 years $^{c}$ & $\mathrm{NI}$ & $\mathrm{NI}$ \\
\hline \multirow[t]{3}{*}{ 7-valent pneumoccocal conjugate vaccine } & 12 months $^{a}$ & 87.1 & 91.7 \\
\hline & 24 months $^{b}$ & $\mathrm{NI}$ & $\mathrm{NI}$ \\
\hline & 5 years $^{c}$ & $\mathrm{NI}$ & $\mathrm{NI}$ \\
\hline \multirow[t]{3}{*}{ Rotavirus } & 12 months $^{a}$ & 80.6 & 86.6 \\
\hline & 24 months $^{\mathrm{b}}$ & $\mathrm{NI}$ & $\mathrm{NI}$ \\
\hline & 5 years $^{c}$ & $\mathrm{NI}$ & $\mathrm{NI}$ \\
\hline $\begin{array}{l}{ }^{a} \text { Birth cohort born } 1 \text { January 2009-31 December } \\
\text { bBirth cohort born } 1 \text { January 2008-31 December } \\
\text { 'Birth cohort born } 1 \text { January 2005-31 December } \\
\text { NI: this vaccine at this age milestone is not incluc } \\
\text { Source: Australian Childhood Immunisation Regi }\end{array}$ & ulation of coverage & & \\
\hline
\end{tabular}

children with the highest 24-month coverage for Aboriginal children observed in the Illawarra Shoalhaven LHD.

At 5 years of age, the proportion recorded as being 'fully immunised' was lower than that at earlier age milestones. There was a small difference between Aboriginal and other NSW children $(84.4 \%$ and $88.9 \%$ respectively) while, for individual LHDs, coverage in Aboriginal children ranged from $0.8 \%$ lower (in Albury [Network with Victoria]) to $14 \%$ lower (in Southern NSW) than in non-Aboriginal children (Tables 4 and 6).

\section{Coverage in adolescents}

NSW Adolescent Vaccination Program coverage data for high school students for 2010 are shown in Table 7. Coverage varies by vaccine and dose with better coverage for the first and second doses of human papillomavirus vaccine
(HPV) and the dose of dTpa in Year 7 attendees. Vaccine coverage by LHD was not available for 2010 .

\section{Vaccines for the elderly (pneumococcal and influenza)}

The proportion of people aged 65 years and over who were vaccinated for influenza in the past 12 months has remained relatively stable and is over $70 \%$ in NSW for the period 2002-2010. However, pneumococcal vaccination (23-valent pneumococcal polysaccharide vaccine; 23vPPV) in the previous 5 years has been steadily rising, although it has remained lower than the influenza coverage estimates. The highest coverage rate for pneumococcal vaccination in the elderly was observed in 2006, the year after its inclusion on the National Immunisation Program (Figure 5).

In 2010, influenza (in the previous 12 months) and pneumococcal (in previous 5 years) vaccine coverage in the 


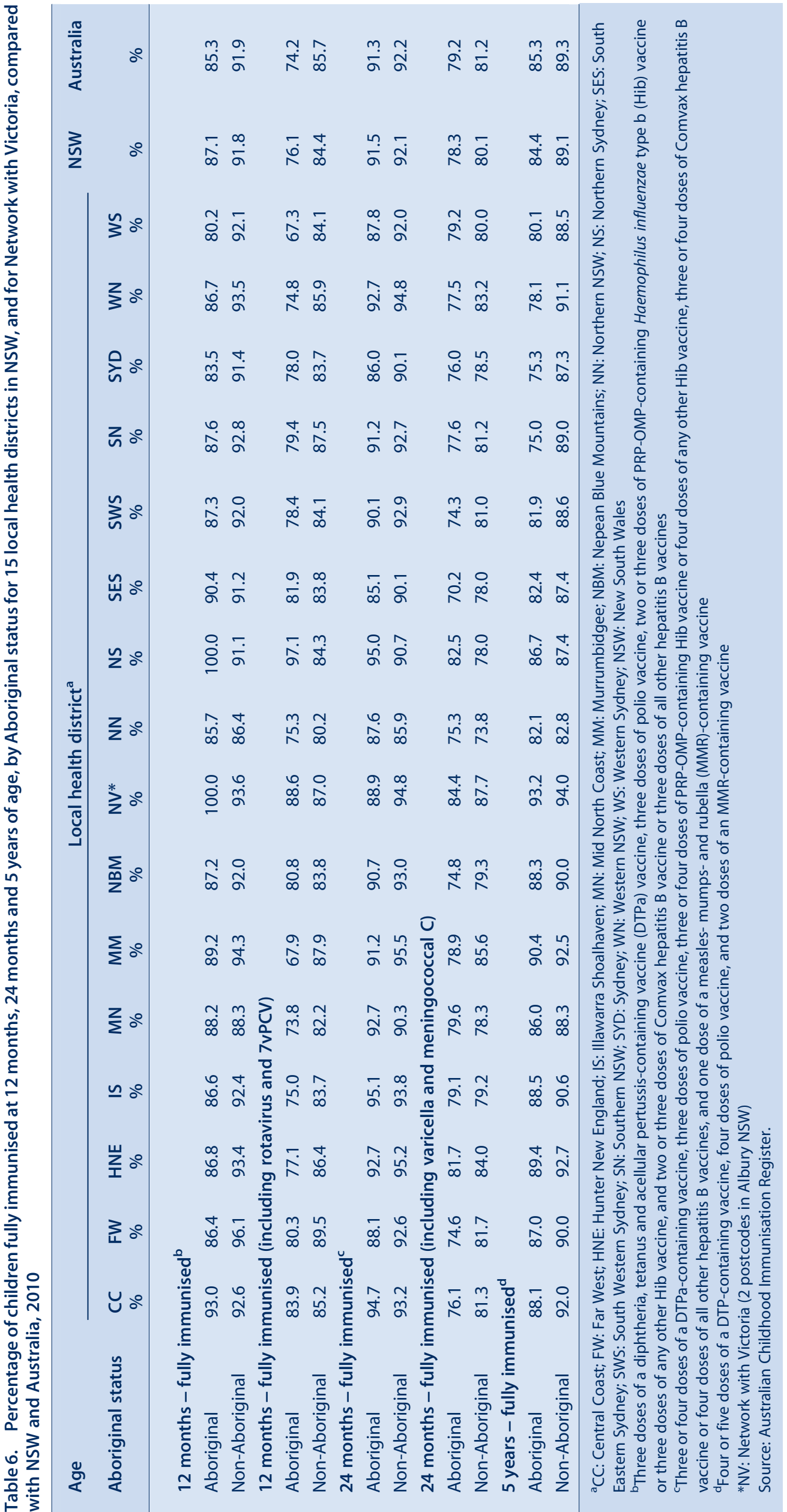


Table 7. Vaccination coverage estimates for individual vaccines, NSW adolescent school attendees in NSW, 2010

\begin{tabular}{|c|c|c|}
\hline Vaccine & $\begin{array}{c}\text { Coverage } \\
(\%)\end{array}$ & $\begin{array}{c}\text { Doses } \\
\text { administered } \\
\text { (n) }\end{array}$ \\
\hline HPV dose $1^{\text {a }}$ & 77 & 32975 \\
\hline HPV dose $2^{\mathrm{a}}$ & 72 & 30793 \\
\hline HPV dose $3^{a}$ & 66 & 28537 \\
\hline Hepatitis $B$ dose $1^{a}$ & 63 & 54701 \\
\hline Hepatitis B dose $2^{a}$ & 57 & 49507 \\
\hline dTpa $a^{a}$ & 70 & 61262 \\
\hline Varicella $^{\mathrm{a}}$ & 32 & 27775 \\
\hline dTpab & 63 & 56384 \\
\hline \multicolumn{3}{|c|}{$\begin{array}{l}\text { ayear } 7 \text { school attendees } \\
\text { bYear } 10 \text { school attendees } \\
\text { HPV: human papillomavirus } \\
\text { dTpa: diphtheria, tetanus, pertussis (acellular) - adolescent and adult } \\
\text { formulation } \\
\text { Source: NSW School Immunisation Program. }\end{array}$} \\
\hline
\end{tabular}

elderly was highest in the Central Coast and Hunter New England LHDs and lowest in the Nepean Blue Mountains LHD. ${ }^{10}$

\section{Timeliness of immunisation}

For the third dose of DTPa, there was significantly greater delay in immunisation for Aboriginal children than nonAboriginal children, with a $16.8 \%$ differential at 7 months of age (Figure 6). A smaller differential of $6 \%$ was found for the second dose of MMR at 49 months of age (Figure 7). There was a marked improvement in the timeliness of the second dose of MMR from 2009 for both population groups, with $28.6 \%$ and $33.3 \%$ of doses given by 50 months of age in Aboriginal and non-Aboriginal children respectively in 2009 , compared to $45.2 \%$ and $51.3 \%$ in 2010 .

A similar pattern is seen when vaccination delay is categorised into 1-6 months and greater than 6 months (Tables 8 and 9). The Northern Sydney LHD had the lowest degree of vaccination delay 1-6 months in length for both Aboriginal and non-Aboriginal children. The Far West LHD had the lowest degree of vaccination delay greater than 6 months in length for both Aboriginal and nonAboriginal children. The LHDs experiencing the greatest overall delay were Northern NSW and the Mid North Coast. The degree of vaccination delay for the second dose of MMR vaccine was substantially higher for all LHDs in NSW and for both Aboriginal and non-Aboriginal children (Table 9). Compared to 2009, the proportion of doses delayed in 2010 by more than 6 months decreased by $4.5 \%$ in Aboriginal and $7.5 \%$ in non-Aboriginal children, while the 1-6-month delays increased by $0.3 \%$ and $3.8 \%$ respectively.

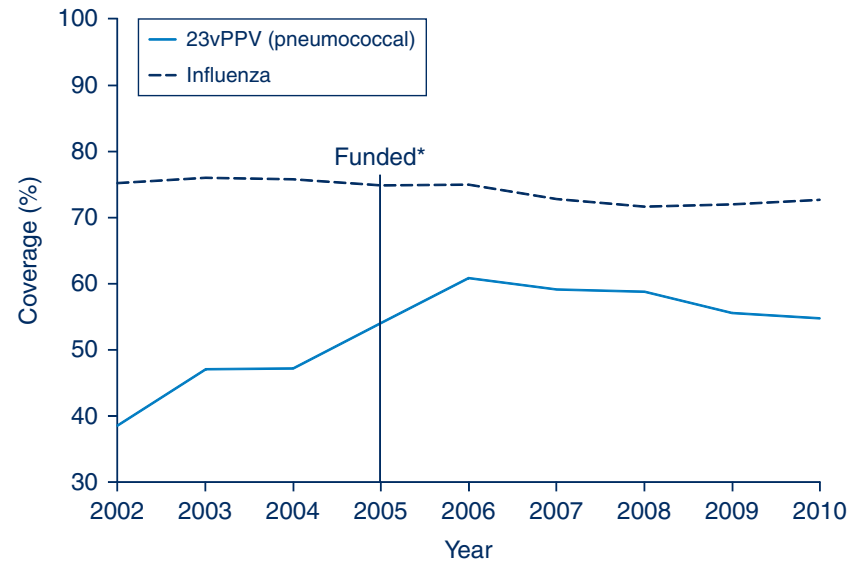

Figure 5. Trends in vaccination coverage estimates for individual vaccines (23vPPV and influenza) for adults aged 65 years and over ${ }^{\mathrm{a}}$ in NSW, 2002-2010

${ }^{a}$ Vaccinated against pneumococcal disease in the last 5 years and vaccinated against influenza in the last 12 months *In 2005, 23vPPV was included in the National Immunisation Program

23vPPV: 23-valent pneumococcal polysaccharide vaccine

Source: NSW Population Health Survey 2010 (HOIST). Centre for Epidemiology and Research, NSW Department of Health.

In response to the current pertussis epidemic and to provide early protection for young infants, it was recommended in March 2009 that NSW immunisation providers give the first dose of DTPa vaccine (given in a hexavalent combination of DPTa, Hep B, Hib and inactivated poliovirus) at 6 weeks of age instead of 8 weeks of age. Figure 8 shows the age at which children in NSW were given the first dose of DTPa by month of vaccination during 2009 and 2010. Before the recommendation, very few children received the vaccine dose at 6 weeks of age but the percentage rose over the 2 years with more than $60 \%$ of children receiving the dose before 8 weeks of age in November 2010.

\section{Conscientious objectors and no vaccines recorded}

The percentage of children with no vaccines recorded in NSW is greater than those recorded as conscientious objectors (Table 10). Both indicators varied by LHD with a high percentage of objectors and children with no vaccines recorded in the Northern NSW LHD and the lowest in the Western NSW LHD.

\section{Small area coverage}

'Fully immunised' coverage in NSW by statistical subdivision for the 5-year milestone age group in 2010 varies substantially within the state, with many areas having recorded coverage below $90 \%$, putting them at higher risk of outbreaks of highly contagious diseases such as measles and pertussis (Figure 9). However, coverage across the state improved markedly from 2009 with many 


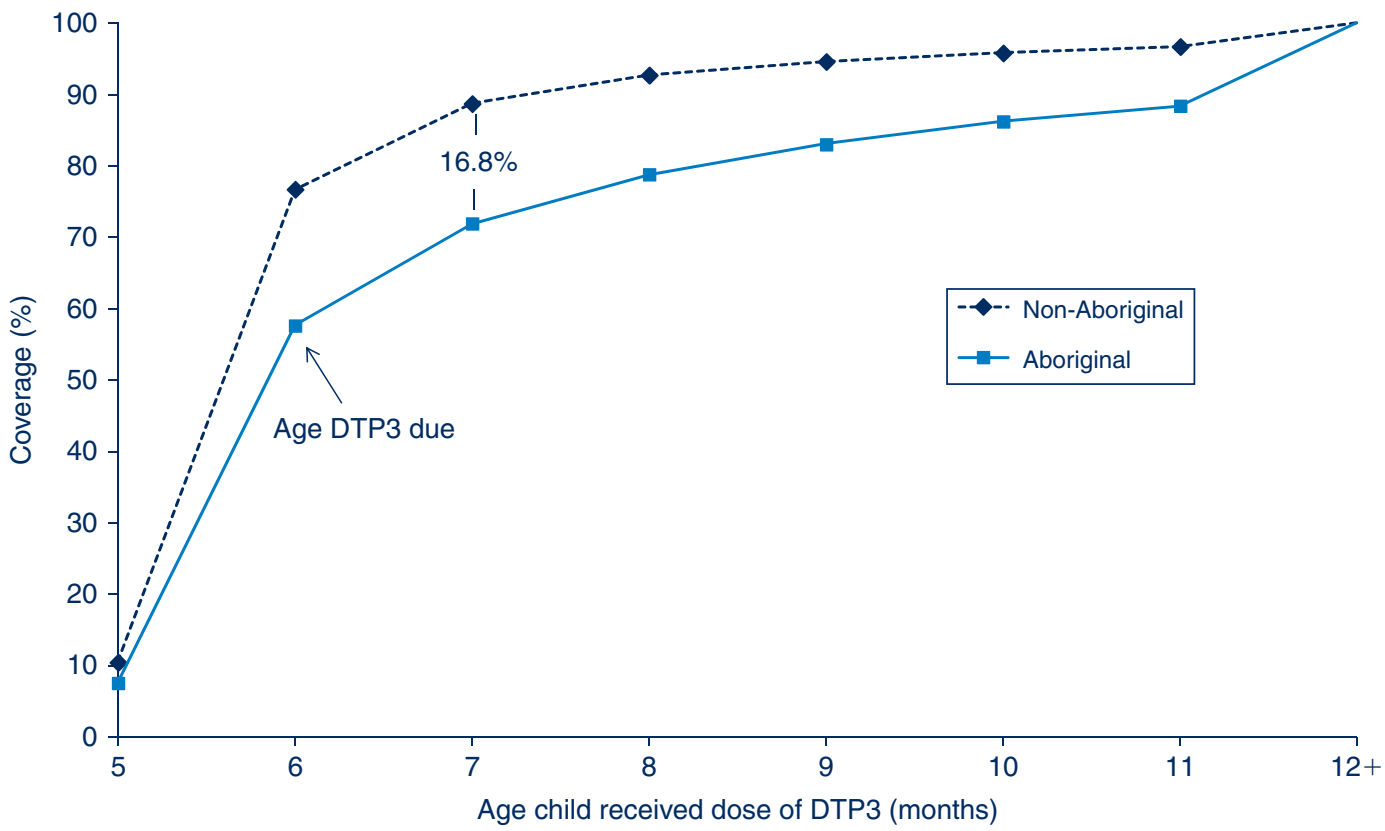

Figure 6. Timeliness of the third dose of diphtheria, tetanus and acellular pertussis-containing (DTPa) vaccine for the cohort of Aboriginal and non-Aboriginal children born in 2007 in NSW

Percentage covered $=$ number of children who received vaccine dose at particular ages/the total number of children who received the vaccine dose

DTP3: third dose of DTPa - paediatric formulation

Source: Australian Childhood Immunisation Register.

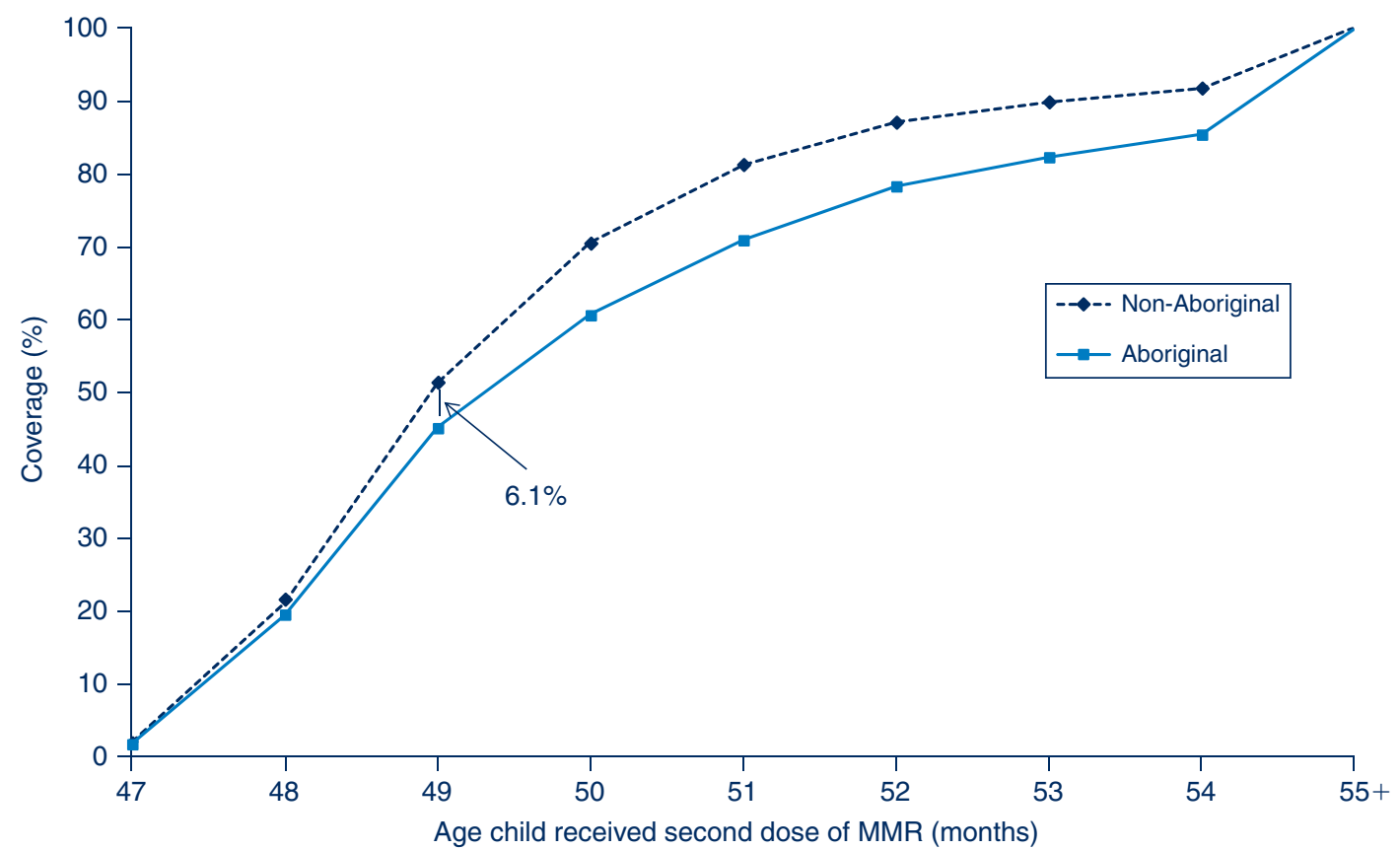

Figure 7. Timeliness of the second dose of measles-mumps-rubella (MMR) vaccine for the cohort of Aboriginal and non-Aboriginal children born in 2004 in NSW

Percentage covered $=$ number of children who received vaccine dose at particular ages/the total number of children who received the vaccine dose

MMR: measles-mumps-rubella

Source: Australian Childhood Immunisation Register. 


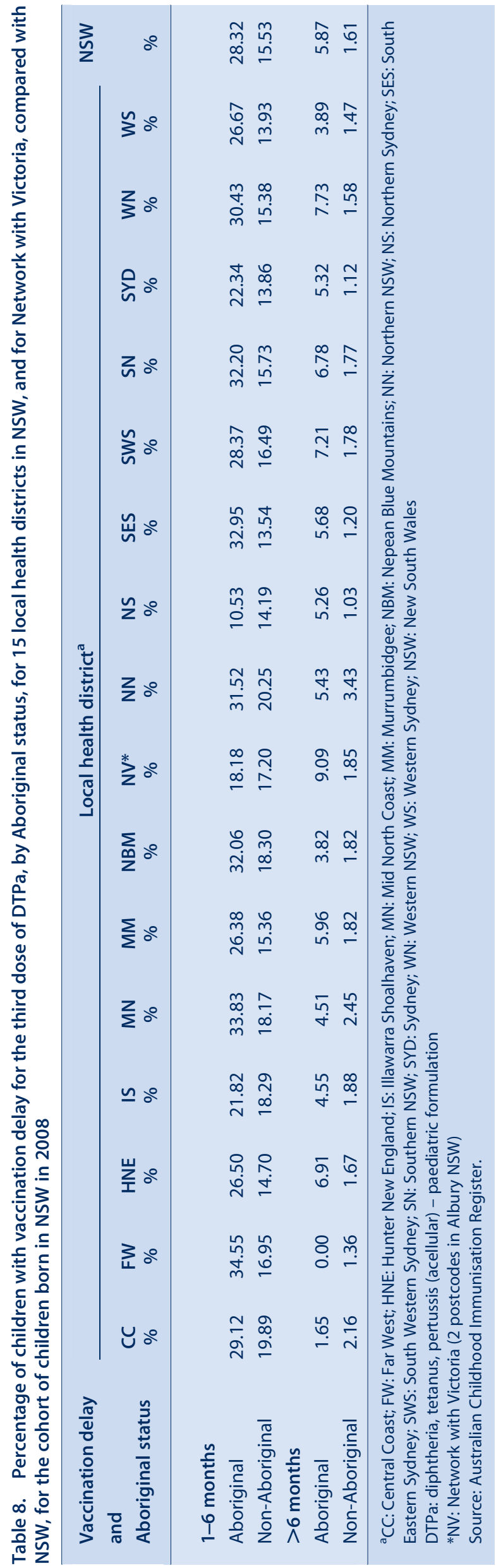

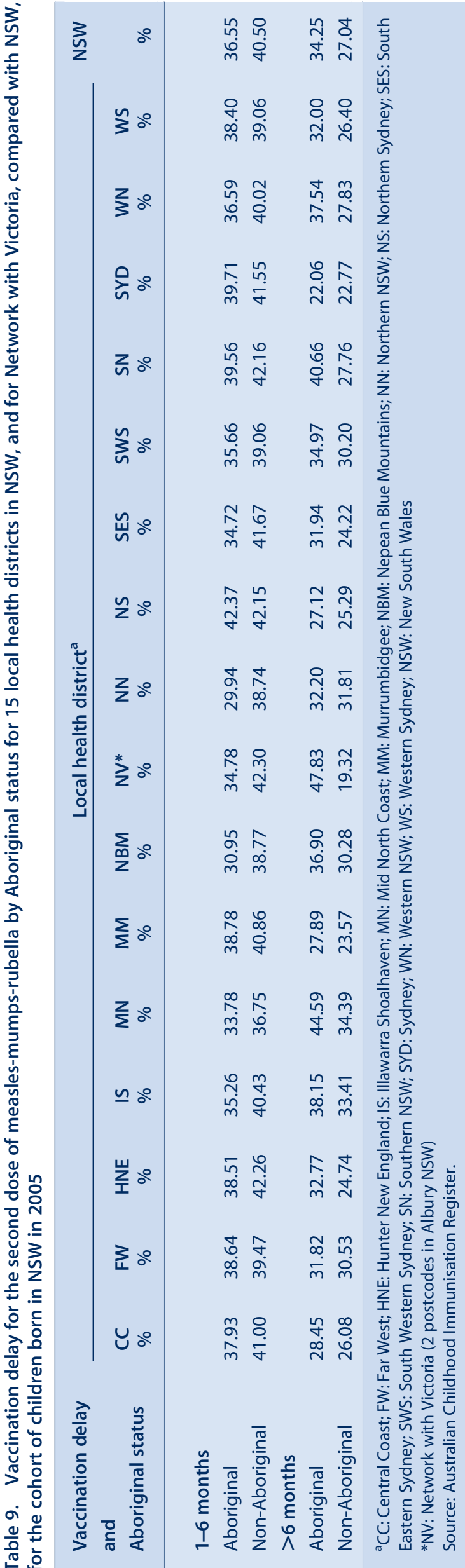




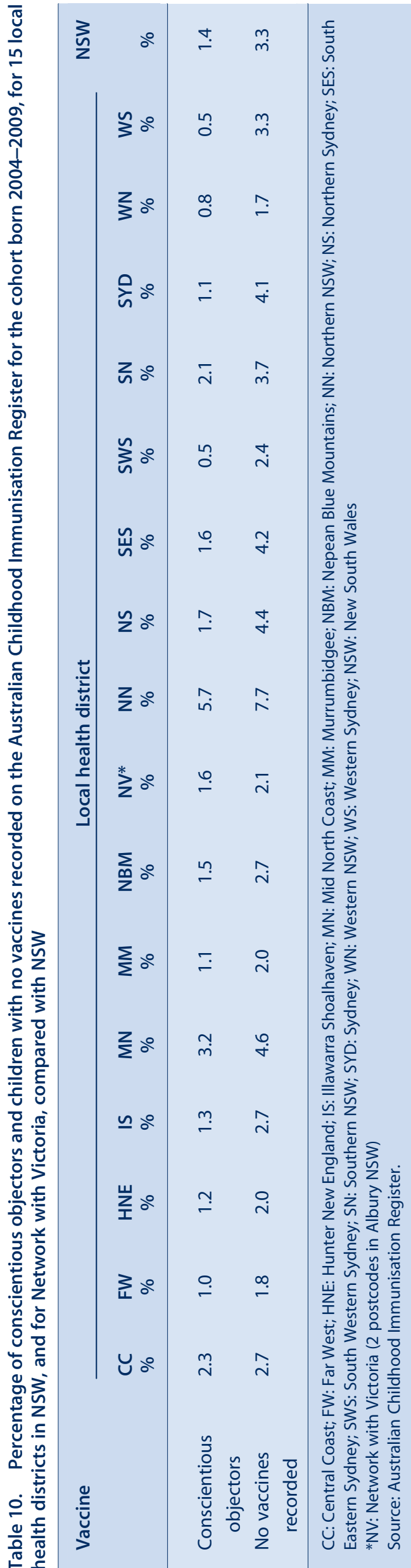

areas, especially outside Sydney, with 'fully immunised' coverage above national benchmark levels.

\section{Discussion}

These data reveal that $90 \%$ coverage benchmarks have been reached for children at both 12 and 24 months of age for NSW and for all LHDs except for Northern NSW and the Mid North Coast. During 2009 and 2010, there was a substantial increase in coverage at the 5-year milestone, to just below the $90 \%$ level.

Coverage at 24 months of age exceeds that at 12 months in NSW and for 10 LHDs. This is likely related to the greater period of time between due date and assessment time (12 and 6 months respectively), and potentially the maternity incentive payment assessed at 18-24 months. The increase in coverage at 5 years is due to improved timeliness of vaccination, and is probably related to the change to the overdue rules in January 2009, where children became overdue for their pre-school boosters at 4 years and 1 month of age instead of the previous 5 years (Box 1). This change had an impact on eligibility for child-care benefits for parents and outcome payments for providers. It was accompanied by a letter from Medicare Australia advising parents of the change, and the follow-up of overdue children by local health authorities. It is unlikely that the splitting of the Maternity Immunisation Allowance at that time could have had an impact on these data, as it applies only to children turning 4 years from 2011 onwards. Older children would have received the full Maternity Immunisation Allowance payment at 24 months of age and were therefore not eligible for another payment at 4 years.

While there was little difference in the coverage for most individual vaccines given at particular schedule points, the exceptions were rotavirus and varicella, for which coverage was substantially lower. The reasons for lower varicella coverage may relate to the age of vaccination (18 months), a schedule point where no other vaccines are due, and where coverage has been lower in the past for other vaccines (i.e. DTPa). ${ }^{1}$ For rotavirus, upper age limits that apply only to this vaccine are likely to reduce vaccinations with this vaccine but not others when children present late.

It should be noted that several vaccines are not included in the assessment of 'fully immunised' (i.e. 7vPCV, meningococcal $\mathrm{C}$, rotavirus and varicella). While this annual report provides coverage data on these vaccines, only data for the more longstanding and established vaccines are provided to General Practice Divisions and immunisation providers. Coverage estimates for the $7 \mathrm{vPCV}$ and meningococcal C vaccines are comparable with estimates for vaccines that are included in 'fully immunised' calculations, but estimates for 


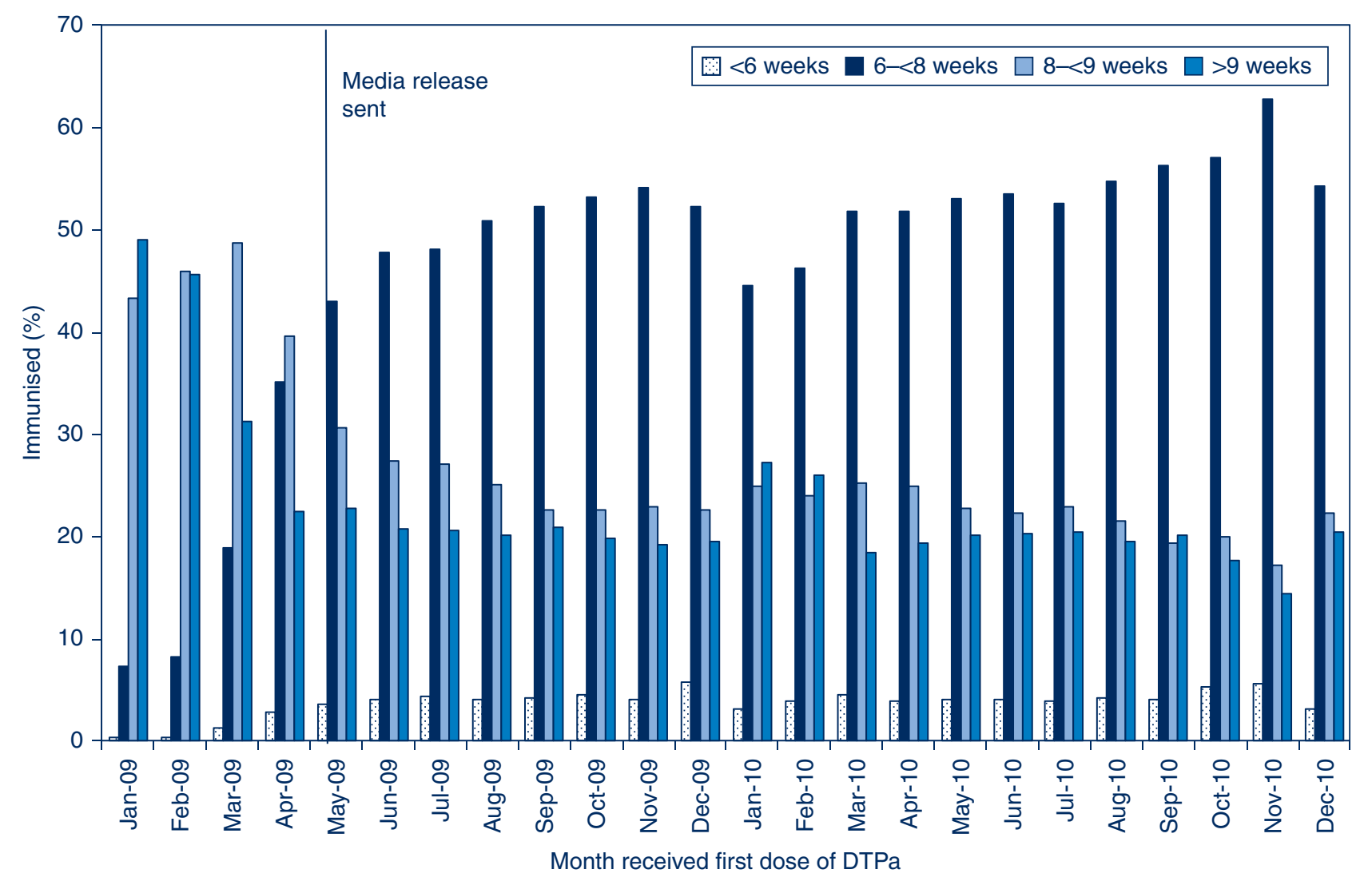

Figure 8. Age at which children in NSW received their first dose of hexavalent combination (DTPa/Hexa) vaccine by month of receipt, January 2009-December 2010

The media release was a message for providers and the public on 10 March 2009 which asked parents and providers to consider bringing the first dose of DTPa forward to 6 weeks of age to provide earlier protection

DTPa/Hexa: hexavalent combination of diphtheria, tetanus, pertussis (acellular), Hep B, Hib and inactivated poliovirus

Source: Australian Childhood Immunisation Register.

varicella and rotavirus are lower. As these vaccines have been routinely incorporated into the childhood immunisation schedule for some time, their inclusion in the official coverage assessments for 'fully immunised', and wider dissemination, should be considered. This would facilitate monitoring of program delivery, potentially boost coverage by allowing existing incentive payments to apply to them, and provide a more realistic assessment of 'fully immunised'.

Although most children eventually complete the scheduled series of vaccinations by the 24-month milestone, many still do not do so in a timely manner. This situation is more pronounced for Aboriginal children, which has been noted previously. ${ }^{1,12}$ It is of particular concern for diseases where multiple vaccine doses are required for protection and the disease risk among young infants is significant (e.g. pertussis and pneumococcal disease), and for Aboriginal children who often suffer infection at an earlier age. Immunisation at the earliest appropriate age should be a public health goal for countries such as Australia where high levels of vaccine coverage at milestone ages have been achieved. Of note was the improved timeliness of the second dose of MMR vaccine from 2009, and the rapid improvement in pertussis vaccination at $6-8$ weeks of age following its promotion in NSW.

Coverage for elderly people has been consistently high for influenza vaccine, but less so for pneumococcal vaccine, perhaps due to greater awareness of the yearly influenza vaccination programs.

School-based vaccination in NSW has achieved relatively high coverage for most vaccines, which is similar to or better than that achieved in other Australian jurisdictions and higher than in settings where adolescent vaccines are implemented through primary care. ${ }^{11}$

\section{Conclusion}

Data provided by the Australian Childhood Immunisation Register in this report reflect the successful delivery of the National Immunisation Program in NSW, while identifying some areas for improvement. The Australian Childhood Immunisation Register, the NSW Population Health Survey and monitoring through the NSW School Vaccination Program continue to be very useful tools for administering the National Immunisation Program and monitoring its implementation in NSW. 


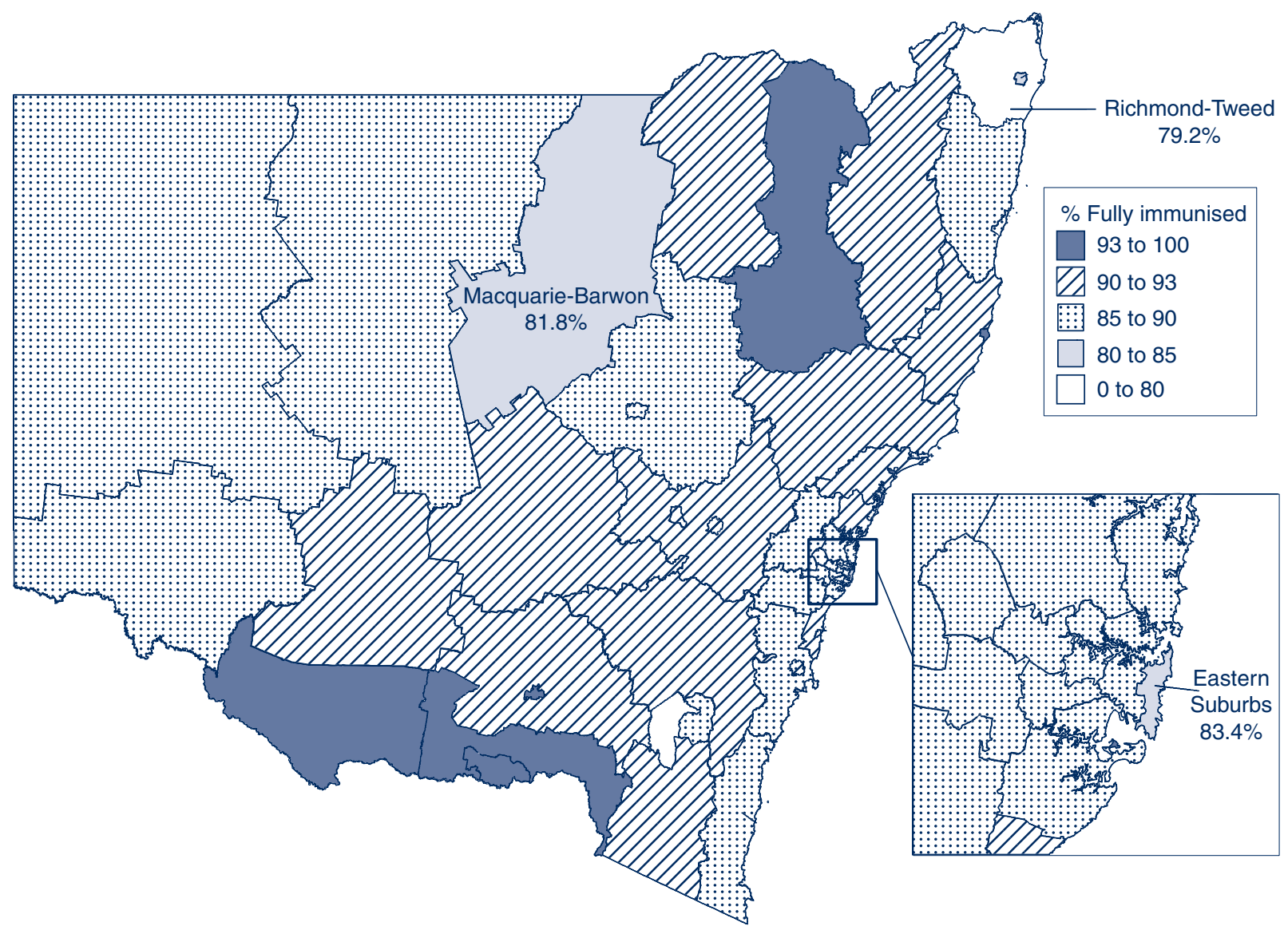

Figure 9. 'Fully immunised' coverage at 5 years of age, by statistical subdivision, NSW, for the cohort of children born in 2005 Source: Australian Childhood Immunisation Register.

\section{References}

1. Hull B, Deeks S, Menzies R, McIntyre P. Immunisation coverage annual report, 2007. Commun Dis Intell 2009; 33: 170-87.

2. Hull BP, Deeks SL, McIntyre PB. The Australian Childhood Immunisation Register - a model for universal immunisation registers? Vaccine 2009; 27: 5054-60. doi:10.1016/ J.VACCINE.2009.06.056

3. Hull BP, McIntyre PB, Heath TC, Sayer GP. Measuring immunisation coverage in Australia. A review of the Australian Childhood Immunisation Register. Aust Fam Physician 1999; 28: 55-60.

4. O'Brien ED, Sam GA, Mead C. Methodology for measuring Australia's childhood immunisation coverage. Commun Dis Intell 1998; 22(3): 36-7.

5. Hull BP, McIntyre PB. Immunisation coverage reporting through the Australian Childhood Immunisation Register an evaluation of the third-dose assumption. Aust $N Z J$ Public Health 2000; 24(1): 17-21. doi:10.1111/J.1467-842X.2000. TB00717.X

6. Hull BP, Lawrence GL, MacIntyre CR, McIntyre PB. Estimating immunisation coverage: is the 'third dose assumption' still valid? Commun Dis Intell 2003; 27(3): 357-61.

7. Rank C, Menzies RI. How reliable are Australian Childhood Immunisation Register coverage estimates for indigenous children? An assessment of data quality and coverage. Commun Dis Intell 2007; 31(3): 283-7.

8. Australian Bureau of Statistics (ABS). Australian Standard Geographical Classification (ASGC), 2001. Cat. no. 1216.0. Canberra: ABS; 2001.

9. Australian Bureau of Statistics (ABS). Statistical Subdivision from Postal Area 2006 Concordance. Canberra: ABS; 2007. Available from: www.abs.gov.au/AUSSTATS/abs@.nsf/ 39433889d406eeb9ca2570610019e9a5/ 5942283858e38743ca25730c00009f2e!OpenDocument (Cited 29 August 2011.)

10. Health NSW. New South Wales Population Health Survey. 2010. Available from: www.health.nsw.gov.au/resources/ publichealth/surveys/pdf/hsa_10pub.pdf (Cited 29 August 2011.)

11. Ward KF, Menzies RI, Quinn HE, Campbell-Lloyd S. School-based vaccination in NSW. N SW Public Health Bull 2010; 21(9-10): 237-42. doi:10.1071/NB10046

12. Hull BP, McIntyre PB. Timeliness of childhood immunisation in Australia. Vaccine 2006; 24: 4403-8. doi:10.1016/ J.VACCINE.2006.02.049 